\title{
Influence of dressing strategy on tool wear and performance behavior in grinding of forming tools with toric grinding pins
}

\author{
Berend Denkena $^{1} \cdot$ Alexander Krödel-Worbes $^{1} \cdot$ Michael Keitel $^{1}$ (1) $\cdot$ Philipp Wolters $^{1}$
}

Received: 17 May 2021 / Accepted: 9 November 2021 / Published online: 2 December 2021

(c) The Author(s) 2021

\begin{abstract}
The performance of grinding tools in grinding processes and the resulting surface and subsurface properties depend on various factors. The condition of the grinding tool after dressing is one of these factors. However, the influence of the dressing process on the condition of the grinding tool depends on the selected process parameters and is difficult to predict. Therefore, this paper presents an approach to describe the influence of the dressing process on tool wear of toric grinding pins and the resulting subsurface modification. For this purpose, toric grinding pins with a vitrified bond were dressed with two different strategies and the wear and operational behavior were investigated when grinding AISI M3:2 tool steel with two different grinding strategies. In general, the investigations have shown that the dressing process influences the performance and wear behavior differently depending on the grinding strategy used. The degree of clogging is influenced by the geometric contact sizes. In the case of small engagement cross sections with simultaneously large contact lengths the thermal tool load is distributed over a small annular area of the tool and favors clogging. Crushing and additional transverse loading of the grains result in an almost clog-free tool surface. This also leads to a lower G-ratio. Crushing leads to an intensified decrease of the torus radii. The influence of the dressing strategy can also be observed in the induced residual stresses. Toric grinding pins dressed by crushing induce lower compressive residual stresses into the workpiece, which can be attributed to the self-sharpening effect. This effect reduces the mechanical and thermomechanical load of the workpiece during machining.
\end{abstract}

Keywords High-speed steel 1.3344 (AISI M3:2) · Toric grinding pins · Dressing · Residual stresses · Wear behavior · Sheet-bulk metal forming

\section{Introduction}

Sheet bulk metal forming is a new class of forming processes and combines the processes of cold forming and bulk metal forming. In this new process sheet metal components with a thickness of up to $3 \mathrm{~mm}$ are cold forged, which enables the integration of functional elements such as gear teeth into

Michael Keitel

keitel@ifw.uni-hannover.de

Berend Denkena

denkena@ifw.uni-hannover.de

Alexander Krödel-Worbes

kroedel@ifw.uni-hannover.de

Philipp Wolters

wolters@ifw.uni-hannover.de

1 Institute of Production Engineering and Machine Tools, Machining Technology, Leibniz University Hannover, An der Universität 2, 30823 Garbsen, Germany the sheet metal component [1]. High forces are necessary to ensure the mold filling capability due to the occurring strain hardening of the material during the forming process, resulting in contact pressures of up to $1.4 \mathrm{GPa}$ and locally varying tensile and compressive loads [2]. These loads significantly contribute to tool wear, placing high demands on the casting tool [3]. Since the performance of highly loaded components can be influenced by the subsurface properties [4], tailored subsurface properties of the forming tools can help to increase service life and performance. The superposition of suitable residual stresses with occurring load stresses can delay a failure of functionally relevant tool areas due to material fatigue. The properties and residual stress states present in the component subsurface are essentially determined by the manufacturing processes used in the process chain [5].

Fine machining by grinding or polishing is one of the final steps in the process chain for manufacturing sheet metal forming tools and therefore determines their 
surface and subsurface properties. Form grinding processes with spherical grinding tools are the most suitable processes for this step in the process chain, since sheet bulk metal forming tools have complex geometries with free-form surfaces. Tönshoff et al. show the suitability of such spherical grinding tools for the machining of multi-curved surfaces using the example of tool and die making [6]. Grinding with toric grinding pins is an enhanced variant of this process. It offers the potential to adjust the subsurface properties locally and load-oriented. In their investigations on grinding of $1.3344 \mathrm{PM}$ steel with toric grinding pins, Denkena et al. show the influence of the process parameters, grain size and grinding strategy on the surface and subsurface properties. They could show that the residual stress state is primarily influenced by feed rate and grain size of the toric grinding pin [7]. Besides the process parameters and the grinding wheel configuration, the surface and subsurface properties are significantly determined by the grinding wheel condition, which in turn is determined by the conditioning process [8]. For the conditioning of grinding tools several processes and setting variables are available. The most important parameters for the dressing process are the dressing speed ratio $q_{d}$, the dressing feed $v_{\text {fad }}$ and the dressing infeed $\mathrm{a}_{\mathrm{edH}}[8,9]$. Previous investigations are mainly related to cylindrical tools. In general, the influence of dressing on wear and application behavior of toric grinding pins has not yet been systematically investigated. The aim of this paper is therefore to present an approach for the description of the influence of the dressing process on tool wear of toric grinding pins and the resulting component subsurface modification.

\section{Materials and experimental setup}

\subsection{Materials}

The powder metallurgical high-speed steel AISI M3:2 (ASP ${ }^{\circledR} 2023$ ) was selected as experimental material. The chemical composition is shown in Table 1. The high-speed steel was heat treated in vacuum at an austenitizing temperature of $1400{ }^{\circ} \mathrm{C}$ and tempered three times at $560{ }^{\circ} \mathrm{C}$ for $1 \mathrm{~h}$ each time. After heat treatment, the material has a hardness of $62 \pm 2$ HRC. The specimens used have a cuboid geometry with dimensions of $43 \times 30 \times 12 \mathrm{~mm}^{3}$.

\subsection{Grinding and dressing process}

\subsubsection{Toric grinding pins}

Vitrified bonded toric grinding pins (Bärhausen, Germany) with a diameter of $\mathrm{T}=30 \mathrm{~mm}$ and a torus radius $\mathrm{r}=5 \mathrm{~mm}$ were used for the investigations. As an abrasive served CBN with a grain size of $\mathrm{d}_{\mathrm{G}}=54 \mu \mathrm{m}$ at a concentration of $\mathrm{C}=125$.

\subsubsection{Dressing process}

Dressing of the toric grinding pins is performed via downdressing by a pulling dressing strategy with a profile forming roll RI12-G4215-125-4-6-R2-40-10-TK, D426-C150 (Dr. Kaiser Diamantwerkzeuge, Germany) with a diameter of $\mathrm{d}_{\mathrm{r}}=125 \mathrm{~mm}$. A C72F105 spindle (Dr. Kaiser Diamantwerkzeuge, Germany) was used as dressing spindle. During the dressing process the rotating toric grinding pin is guided over the dressing tool with the dressing feed $\mathrm{v}_{\text {fad }}$ and the dressing infeed $\mathrm{a}_{\mathrm{edH}}$. By repeating the process with the respective infeed $\mathrm{a}_{\mathrm{edH}}$ between the dressing strokes, the grinding wheel profile is thus created according to the principle of profiling. A schematic illustration of the dressing process as well as the movements of the toric grinding pin are shown in Fig. 1.

The parameters used in the dressing processes are shown in $\mathrm{n}_{\mathrm{r}}$ : dressing spindle speed, $\mathrm{n}_{\mathrm{sd}}$ : toric grinding pin speed.

In Table 2, two different combinations of dressing parameters with a constant dressing coverage of $\mathrm{U}_{\mathrm{d}}=4 \mathrm{~s}$ were selected for the investigations. In addition, the dressing parameters were chosen so that the combination A1 had a speed ratio of $q_{d}=1$. The speed ratio $q_{d}$ is the ratio of the circumferential speed of the grinding tool to the circumferential speed of the dressing spindle (1). A dressing process with a speed ratio of $\mathrm{q}_{\mathrm{d}}=1$ is called crushing. When dressing the grinding tool bond by crushing, the material is removed from the grinding tool by crushing of bond bridges due to the pressure exerted by the profile forming roll. In addition, crushing of the bond leads to microcracks in the bond, which facilitate crack propagation and allow the bond layers to break out at lower process forces. For the combination A2 a speed ratio of $\mathrm{q}_{\mathrm{d}}=0.8$ was chosen.

$q_{d}=\frac{v_{c r}}{v_{c s}}$

with: $\mathrm{v}_{\mathrm{cs}}$ : tool cutting velocity during dressing, $\mathrm{q}_{\mathrm{d}}$ : speed ratio, $\mathrm{v}_{\mathrm{cr}}$ : dressing spindle velocity.
Table 1 Chemical composition of AISI M3:2 [10]

\begin{tabular}{lllllll}
\hline [wt\%] & $\mathrm{C}$ & $\mathrm{Cr}$ & $\mathrm{Mo}$ & $\mathrm{W}$ & $\mathrm{V}$ & $\mathrm{Fe}$ \\
\hline AISI M3:2 & 1.28 & 4.00 & 5.00 & 6.40 & 3.1 & Balanced \\
\hline
\end{tabular}




\subsubsection{Grinding with toric grinding pins}

The grinding experiments were carried out on an RMF 600 DS (Röders Tec, Germany) machine tool. Two principal grinding strategies, frontal and lateral, can be used when grinding with toric grinding pins (cf. Fig. 2). In the frontal strategy, the cutting speed $\mathrm{v}_{\mathrm{c}}$ and the feed speed $\mathrm{v}_{\mathrm{f}}$ are oriented orthogonally to each other. In the lateral strategy,
Fig. 1 Schematic illustration of the dressing process. $n_{r}$ dressing spindle speed, $n_{s d}$ toric grinding pin speed

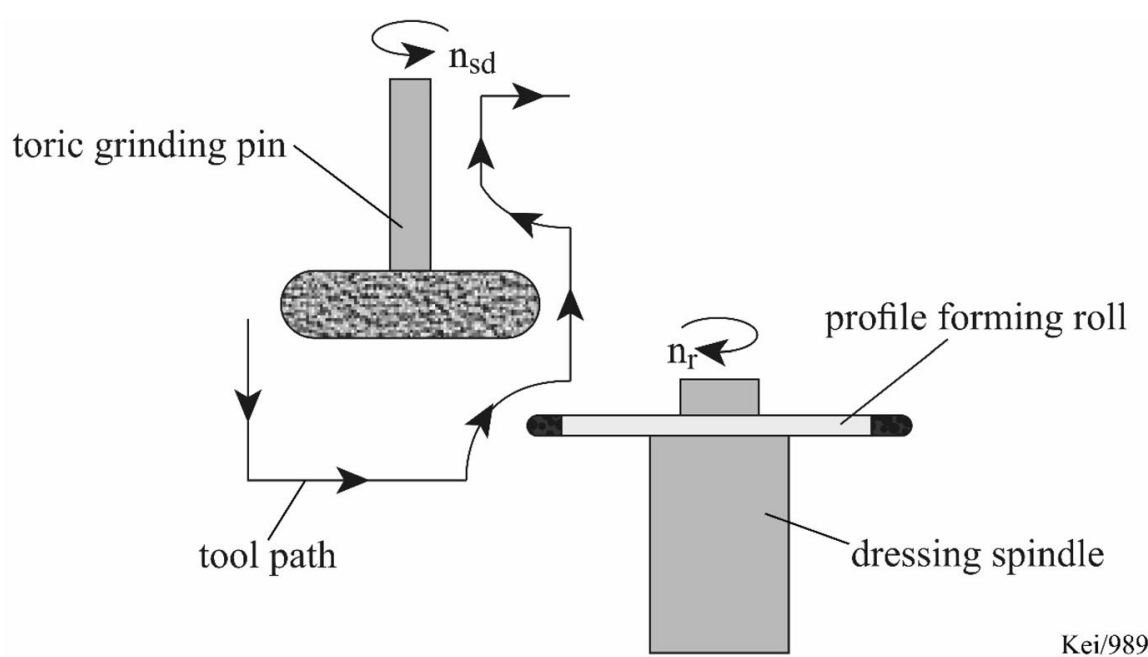

Kei/98992@IFW
Table 2 Parameters for the dressing process

\begin{tabular}{lllllll}
\hline Combination & $\mathrm{v}_{\mathrm{cs}}[\mathrm{m} / \mathrm{s}]$ & $\mathrm{v}_{\mathrm{cr}}[\mathrm{m} / \mathrm{s}]$ & $\mathrm{v}_{\mathrm{fad}}[\mathrm{mm} / \mathrm{min}]$ & $\mathrm{a}_{\mathrm{edH}}[\mathrm{mm}]$ & Strokes & $\mathrm{q}_{\mathrm{d}}$ \\
\hline A1 (crushed) & 20 & 20 & 398 & 0.003 & 25 & 1 \\
A2 & 30 & 24 & 597 & 0.003 & 25 & 0.8 \\
\hline
\end{tabular}

$v_{c s}$ tool cutting velocity during dressing, $q_{d}$ speed ratio, $v_{c r}$ dressing spindle velocity, $a_{e d H}$ dressing infeed per stroke, $v_{\text {fad }}$ axial dressing feed rate

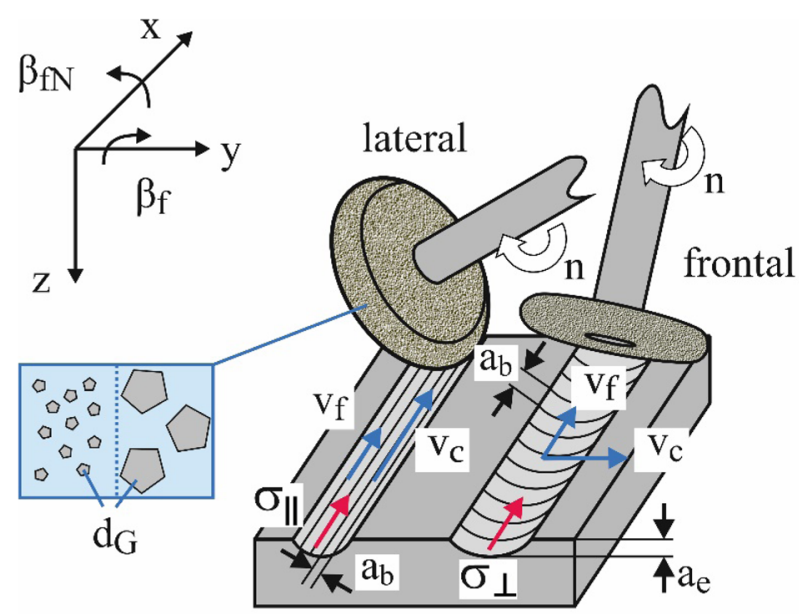

$a_{\mathrm{e}} \quad$ depth of cut

$v_{f}$ feed rate

$\mathrm{r}$ torus minor radius

$B_{f}$ lead angle

$\beta_{\mathrm{fN}}$ tilt angle

$\sigma_{\|} \quad$ residual stresses parallel to cutting direction

$\sigma_{\perp}$ residual stresses transversal to cutting direction

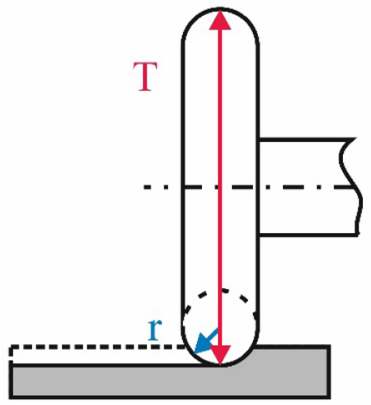

ab path distance

$\mathrm{v}_{\mathrm{c}} \quad$ cutting speed

$\mathrm{T}$ torus main diameter

$\mathrm{d}_{\mathrm{G}} \quad \mathrm{CBN}$ grain size

Fig. 2 Grinding parameters for grinding with toric grinding pins [11] 
cutting speed $\mathrm{v}_{\mathrm{c}}$ and feed speed $\mathrm{v}_{\mathrm{f}}$ are parallel to each other. In the investigations conducted, both the frontal and lateral grinding strategies were used for both dressing strategies. The experiments were repeated once. The applied process parameters are listed in Table 3.

For grinding with toric grinding pins, the contact conditions can be described by the contact length $l_{g}$ and contact width $b_{g}$. Depending on the used grinding strategy, these contact conditions are formed differently. Figure 3 shows the geometric contact values of contact length and contact width for lateral and frontal grinding strategy. For the lateral grinding strategy inclination is realized transverse to feed direction via the tilt angle $\beta_{\mathrm{fN}}$, for frontal grinding in feed direction inclination is realized via the lead angle $\beta_{\mathrm{f}}$. Due to a lead angle $\beta_{\mathrm{f}}=30^{\circ}$ and a tilt angle $\beta_{\mathrm{fN}}=30^{\circ}$ used in this investigation, the contact width $\mathrm{b}_{\mathrm{g}}$ is always larger for the frontal grinding strategy than for the lateral grinding strategy. The contact length $l_{\mathrm{g}}$ is always smaller for the frontal grinding strategy than for the lateral strategy [12].

For the geometric contact conditions, a fundamental distinction needs to be made between the first path and the subsequent paths due to the overlap of the toric grinding pin. The parameters describing the contact conditions, like the contact width $b_{g}$, contact length $l_{g}$ and contact cross section $\mathrm{A}_{\mathrm{gg}}$ for the first path were calculated according to the formulae (2)-(5) for the lateral grinding strategy. The calculation of the parameters is described in detail in $[13,14]$.

$b_{g S}=2 l_{g F}=\frac{\pi r}{90} \arccos \left(\frac{r-a_{e}}{r}\right)$

$2 l_{g S}=b_{g F}=\frac{\pi T}{90} \arccos \left(\frac{T-a_{e}}{T}\right)$

$A_{g, 1, S}=\frac{r^{2}}{2}\left(\frac{\pi \cos ^{-1}\left(\frac{r-a_{e}}{r}\right)}{90}-\sin \alpha\right)$

with $\alpha=\sin \left(2 \cos ^{-1}\left(\frac{r-a_{e}}{r}\right)\right)$

The description of the output variables of the toric grinding pins is based on the wear mechanism of clogging and on a consideration of the G-ratios. In the case of clogging, it is a

Table 3 Parameters of the experimental setup

\begin{tabular}{llll}
\hline Cutting speed & $\mathrm{v}_{\mathrm{c}}=30 \mathrm{~m} / \mathrm{s}$ & Depth of cut & $\mathrm{a}_{\mathrm{e}}=30 \mu \mathrm{m}$ \\
Feed rate & $\mathrm{v}_{\mathrm{f}}=500 \mathrm{~mm} /$ & Path distance & $\mathrm{a}_{\mathrm{b}}=0.3 / 0.5 \mathrm{~mm}$ \\
min & $\begin{array}{c}\text { Tilt and lead } \\
\text { angle }\end{array}$ & $\beta_{\mathrm{f}} / \beta_{\mathrm{fN}}=30^{\circ}$ \\
\hline
\end{tabular}

matter of the clogging/closure of the pores by welded chips. The G-ratio is the ratio of the machined volume $V_{\text {Wst }}$ to the volume of material of the worn tool $\mathrm{V}_{\mathrm{WZ}}$. It can therefore be calculated according to the formulae (6) and (7). In the presented study the torus radii were measured at 10 measuring points on each toric grinding pin in order to calculate the G-ratio.

$G=\frac{V_{W s t}}{V_{W Z}}$

$V_{W Z}=\frac{90 \pi}{360} *\left(r_{T, v}^{2}-r_{T, n}^{2}\right) * \pi r_{T, n}$

with: $\mathrm{r}_{\mathrm{T}, \mathrm{v}}$ : torus radius before grinding, $\mathrm{r}_{\mathrm{T}, \mathrm{n}}$ : torus radius after grinding.

\subsection{Surface measurements}

The measurements of the geometry of the toric grinding pins and of their wear were performed using a Helicheck measuring machine (Walter AG, Germany) and an Infinity Focus XL200 G5 topography measuring device (Alicona Imaging $\mathrm{GmbH}$, Austria). The topography measurements were evaluated using the software " $\mu$ soft analysis premium 7.11”(B) (NanoFocus AG, Germany).

\subsection{Residual stress measurements}

The residual stresses are measured by using the $\sin ^{2} \psi$-method in $\omega$-mode as described by Macherauch and Müller [15]. A Seifert 3003 TT dual-circuit diffractometer system (GE Inspection Technologies, Germany) with a $\mathrm{Cr}$-anode in combination with a V-filter and a collimator with a diameter of $d_{c}=2 \mathrm{~mm}$ is used for the measurement. The measurement is performed with an anode current of $\mathrm{I}_{\mathrm{a}}=35 \mathrm{~mA}$ and an accelerating voltage of $\mathrm{U}_{\mathrm{a}}=30 \mathrm{kV}$, with an information depth of $\tau_{\max }=5.5 \mu \mathrm{m}$. The Bragg reflections and elastic constants used for the workpiece material AISI M3:2 are listed in Table 4.

\section{Results}

\subsection{Condition of the toric grinding pins}

The condition of the toric grinding pins after dressing and after grinding is measured in the surfaces in the contact area and in the torus radius. In the case of the toric grinding pin surfaces, a qualitative evaluation of the initial state and the clogging after the grinding process is carried out. When the toric grinding pins are adjusted to $\beta_{\mathrm{fN}}=30^{\circ}$, the contact geometry in the contact area can be described by the torus 
Fig. 3 Geometric contact conditions for grinding with toric grinding pins [12]

\section{frontal strategy}

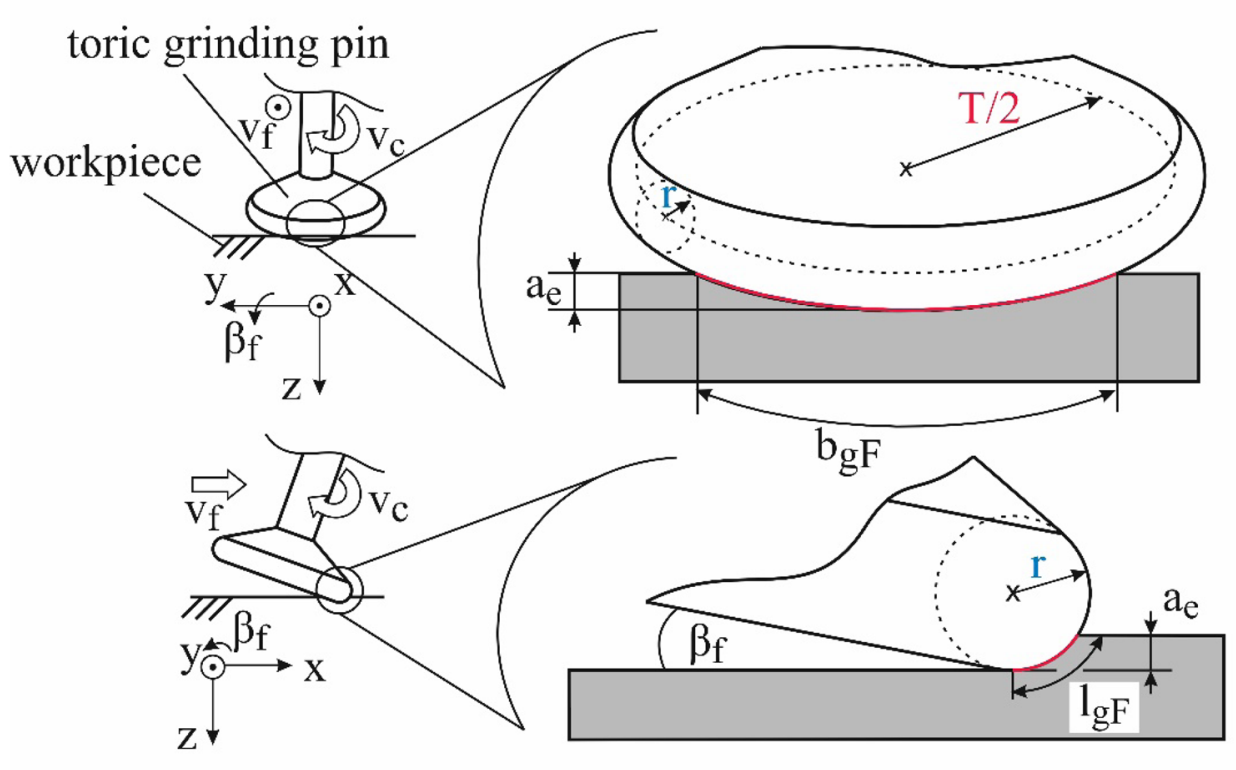

lateral strategy
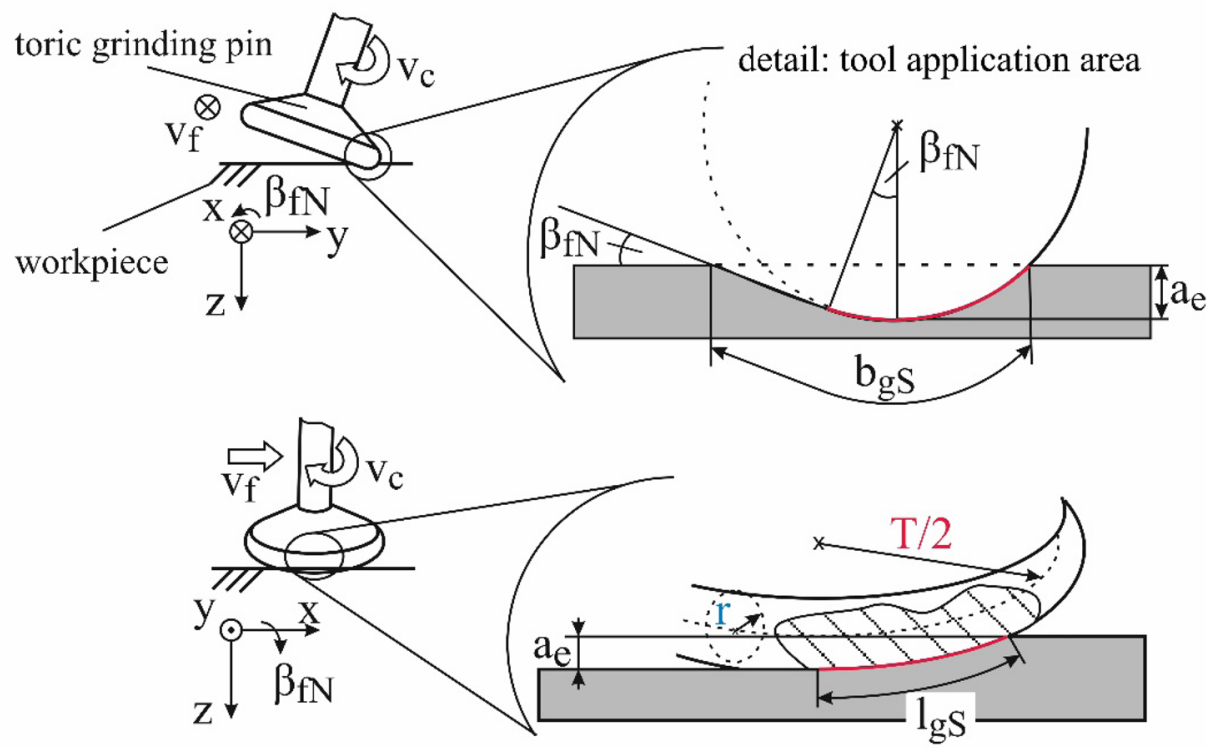

Kei/98991CIFW
Table 4 Specific parameters used for residual stress measurements

\begin{tabular}{llll}
\hline Anode material & $\mathrm{Cr} \mathrm{K} \alpha$ & $\begin{array}{l}\text { Specimen mate- } \\
\text { rial }\end{array}$ & $\alpha$-iron \\
\hline Bragg angle 2 $\Theta$ & $156.1^{\circ}$ & Lattice plane hkl & 211 \\
Poisson's ratio & 0.28 & Young's modulus & $220.264\left[\mathrm{~N} / \mathrm{mm}^{2}\right]$ \\
Elastic constant & $5.81 \mathrm{E}-6$ & Elastic constant & $1.27 \mathrm{E}-6$ \\
$1 / 2 \mathrm{~s}_{2}$ & {$\left[\mathrm{~mm}^{2} / \mathrm{N}\right]$} & $\mathrm{s}_{1}$ & {$\left[\mathrm{~mm}^{2} / \mathrm{N}\right]$} \\
\hline
\end{tabular}

radius $r$, which makes it an important parameter. Furthermore, this parameter is an indicator for the form accuracy of the dressing process, which allows the description of the influences of the contact geometry between toric grinding pin and workpiece. The description of the wear behavior of the toric grinding pins in dependence on the dressing strategy and grinding strategy is done by the G-ratio in addition to the consideration of the toric grinding pin surfaces. Due 
to the rotational symmetry of the toric grinding pins, the calculation is based on the ratio of the torus radius before and after the grinding process. The higher the G-ratio, the more favorable is the wear behavior of the toric grinding pins.

A target value of $r=5 \mathrm{~mm}$ is aimed for the torus radius after dressing. The contour measurement after the dressing process results in a torus radius of $\mathrm{r}=5.04 \pm 0.008 \mathrm{~mm}$ for dressing combination A1 (crushed, $\mathrm{q}_{\mathrm{d}}=1$ ) which means a tolerance of about $0.16 \%$ to the target value. For dressing combination $A 2\left(\mathrm{q}_{\mathrm{d}}=0.8\right)$, a torus radius of $\mathrm{r}=4.89 \pm 0.007 \mathrm{~mm}$ is measured which means a tolerance of about $0.14 \%$ to the target size. Due to the small deviations, it can be assumed that the form tolerance has no influence on the operational and wear behavior. The initial condition of the toric grinding pin surfaces after dressing is shown in Fig. 4 for both dressing processes. Both dressing processes lead to a high degree of porosity of the surfaces, which is common for toric grinding pins with a vitrified bond. Cracks, clogging or other contaminations are not visible. Overall, the surfaces show qualitatively comparable dressing results.

The surfaces of the toric grinding pins after machining a volume of $\mathrm{V}_{\mathrm{Wst}}=804 \mathrm{~mm}^{3}$ are shown in Fig. 5. The qualitative representation of the tool surfaces shows the influence of different grinding and dressing strategies on clogging. Toric grinding pins used with the frontal grinding strategy (Fig. 5, top) show qualitative differences in the clogging of the surface depending on the two dressing processes. Tools dressed by crushing (dressing strategy A1) show a porous, almost clog-free surface, which is comparable to the initial surface. The almost clog-free condition of the crushed tools can be explained by the operating principle of the dressing process and by the additional transverse forces acting on the pin due to the process kinematics in the case of the frontal grinding strategy [7]. In crushing, as described in Sect. 2, dressing is performed by crushing the bond, which leads to microcracks in the bond, and facilitates crack propagation and allow the bond layers to break out at lower process forces. This promotes the self-sharpening effect. The additional transverse forces that are a result of the frontal grinding strategy also promote this. However, the early self-sharpening leads to faster tool wear and thus to lower G-ratios (see Fig. 6). In contrast, clogging occurs on tools dressed with dressing strategy A2 and used with the frontal grinding strategy. In dressing strategy A2, the dressing process is performed by grinding off the bond and abrasive grit, which does not promote self-sharpening. Toric grinding pins used in the lateral grinding strategy (Fig. 5, bottom) show clogging on the surface for both dressing processes. Significant differences are not evident.

The different amounts of clogging depending on the grinding strategy can be explained in terms of the different geometric contact variables (cf. Fig. 3; Table 5). For the lateral grinding strategy the contact length $1_{\mathrm{g}}$ is about twice as great for the first path and greater by a factor of 4.7 for all other paths, compared to the frontal strategy. The contact width $\mathrm{b}_{\mathrm{g}}$ for the frontal grinding strategy, however, is more than twice as great for the first path compared with the lateral grinding strategy, and by a factor of 2.5 greater for all further paths. This results in a higher contact cross section $\mathrm{A}_{\mathrm{g}}$ for the frontal grinding strategy, which is about twice as large for the first path and 50\% larger for all other paths than for the lateral grinding strategy. Due to the small cross section with a simultaneously large contact length for the lateral grinding strategy, the thermal tool load is distributed over a small annular area of the toric grinding pin. The higher temperatures and smaller chip thicknesses can lead to chip adhesion and clogging being favored in the lateral grinding strategy.

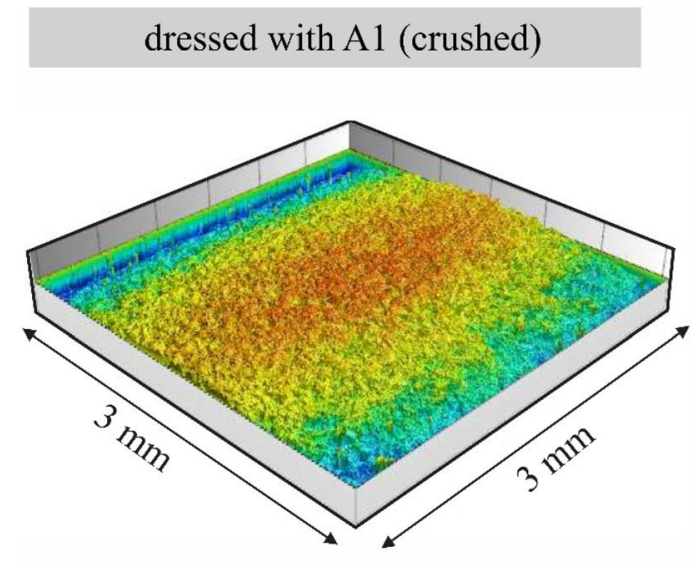

dressed with A2

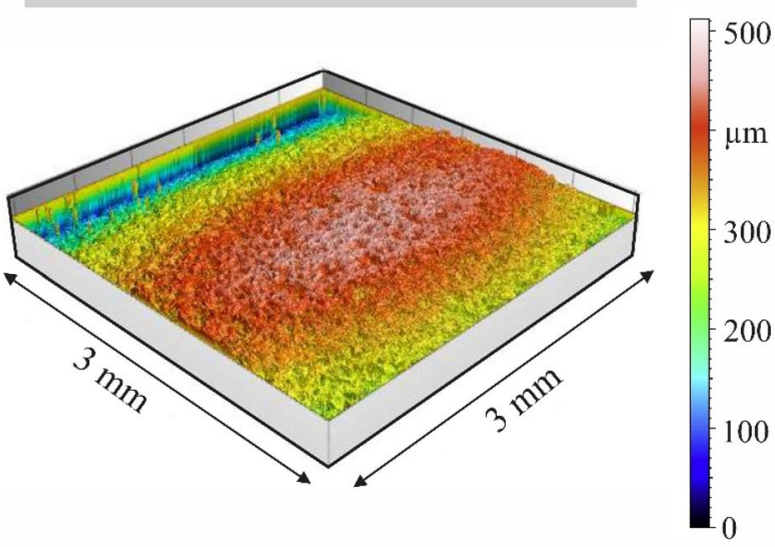

Kei/98986 CIFW

Fig. 4 Surfaces of toric grinding pins after dressing with two different strategies 


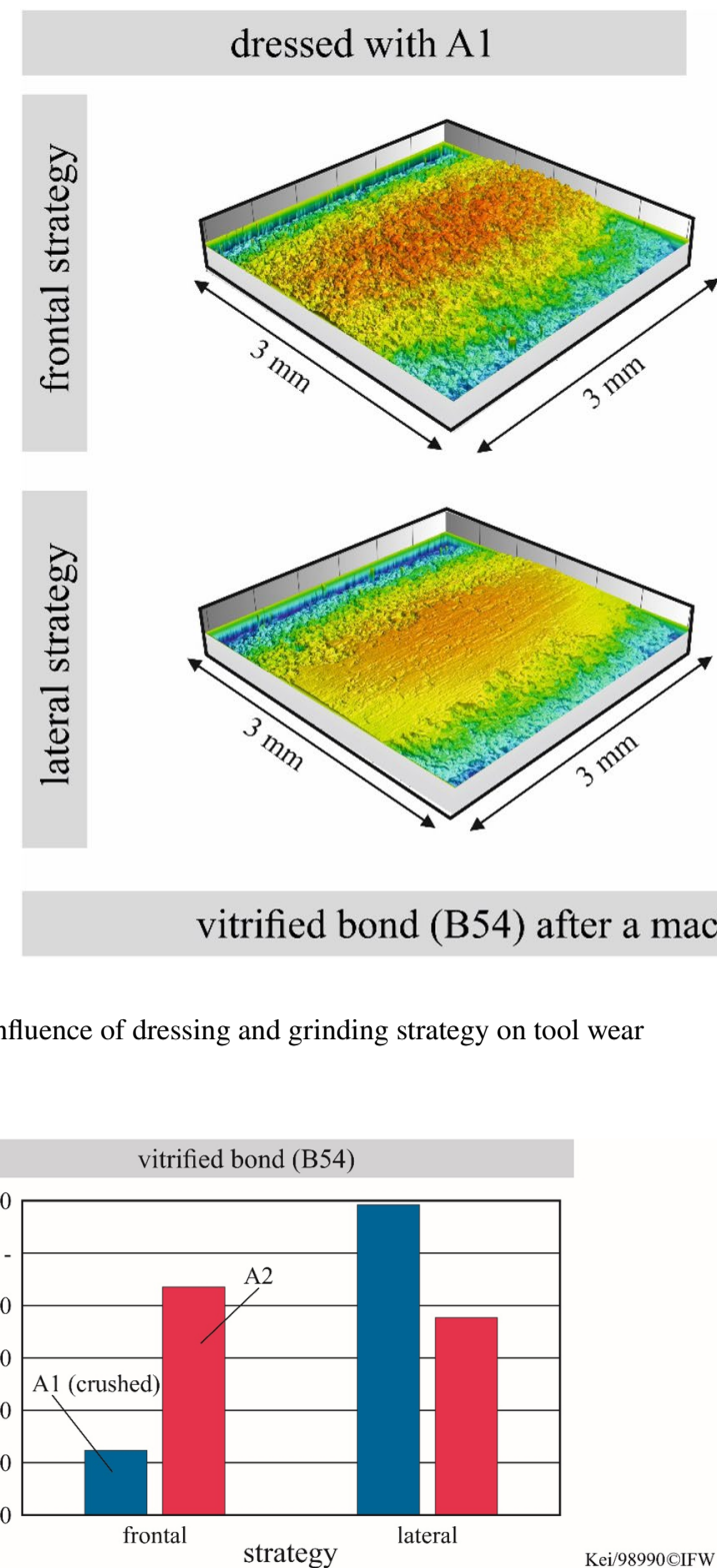

Fig. 6 G-ratios depending on the dressing and grinding strategy

An analysis of the G-ratios for the frontal grinding strategy shows that crushed toric grinding pins have a lower G-ratio by a factor of 4.8. For the lateral grinding strategy the opposite behavior can be observed. These differences can be explained by the grain load in the respective grinding strategy. In the case of the frontal grinding strategy, there is an additional transverse load on the abrasive grain as a result of the orthogonally aligned cutting and feed movements. The resulting shear forces are not present in the lateral grinding strategy. The transverse load acting on the toric grinding pin, in combination with the active principle of crushing, leads to premature breakout of the bond and the abrasive grains. Why the dressing strategy does not seem to have any influence on the clogging in the case of the lateral strategy and why the opposite behavior is observed with the G-ratios could not be conclusively clarified within the context of the present study and requires further investigations.

\subsection{Influence of dressing strategy on subsurface modification}

For each specimen, XRD $\sin ^{2} \psi$-measurements were made after a defined machined volume. The results of these residual stress measurements as a function of the machined volume and the dressing strategy are shown in Fig. 7. Higher compressive residual stresses are induced orthogonal to
Table 5 Geometric contact variables for the frontal and lateral grinding strategy

\begin{tabular}{lllllll}
\hline & $\begin{array}{l}\mathrm{b}_{\mathrm{g}}[\mathrm{mm}] \\
(1 \mathrm{st} \text { path })\end{array}$ & $\begin{array}{l}\mathrm{b}_{\mathrm{g}}[\mathrm{mm}] \\
\text { (nth path) }\end{array}$ & $\begin{array}{l}1_{\mathrm{g}}[\mathrm{mm}] \\
\text { (1st path) }\end{array}$ & $\begin{array}{l}\mathrm{l}_{\mathrm{g}}[\mathrm{mm}] \\
\text { (nth path) }\end{array}$ & $\begin{array}{l}\mathrm{A}_{\mathrm{g}}\left[\mathrm{mm}^{2}\right] \\
\text { (1st path) }\end{array}$ & $\begin{array}{l}\mathrm{A}_{\mathrm{g}}\left[\mathrm{mm}^{2}\right] \\
\text { (nth path) }\end{array}$ \\
\hline Frontal & 2.448 & 1.725 & 0.583 & 0.223 & 0.049 & 0.024 \\
Lateral & 1.096 & 0.698 & 1.207 & 1.229 & 0.022 & 0.016 \\
\hline
\end{tabular}




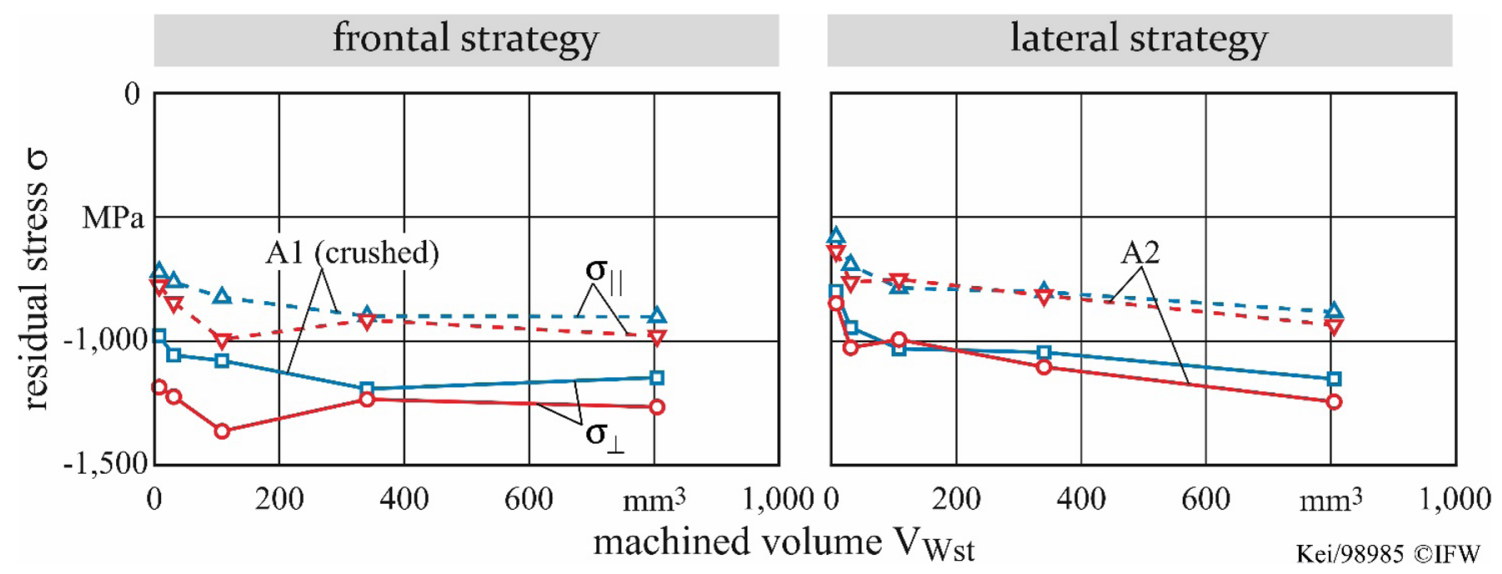

Fig. 7 Residual stress as a function of dressing strategy and machining strategy

the cutting direction. The difference between the parallel and orthogonal induced residual stresses is on average $\Delta \sigma=269 \mathrm{MPa}$ for the frontal strategy for dressing combination A1 (crushed, $\mathrm{q}_{\mathrm{d}}=1$ ) and $\sigma=353 \mathrm{MPa}$ for dressing combination $\mathrm{A} 2\left(\mathrm{q}_{\mathrm{d}}=0.8\right)$. For the lateral strategy, there is an average difference of $\sigma=246 \mathrm{MPa}$ for dressing combination $\mathrm{A} 1$ and $\sigma=263 \mathrm{MPa}$ for dressing combination A2. The different residual stress values in the parallel and orthogonal directions for both strategies can be explained by plastic deformation of the material due to machining. When the toric grinding pin exits the cutting path, residual stresses are induced into the subsurface due to the plastic deformation of the material. Parallel to the cutting direction, part of the subsurface and thus part of the already plastically deformed material is removed as chips by further machining. In contrast, the generated subsurface orthogonal to the cutting direction remains completely unaffected [7].

First of all, a rapid increase in the compressive residual stresses can be observed for the toric grinding pins used up to a machined volume of approx. $\mathrm{V}_{\mathrm{Wst}}=110 \mathrm{~mm}^{3}$ for the frontal grinding strategy and up to approx. $\mathrm{V}_{\mathrm{Wst}}=40 \mathrm{~mm}^{3}$ for the lateral grinding strategy. For toric grinding pins dressed with combination A2 (red line), a drop in compressive residual stresses to the level of the blue curves can be seen for both grinding strategies after a machined volume of $110 \mathrm{~mm}^{3}$ and $40 \mathrm{~mm}^{3}$ respectively. For the frontal grinding strategy, there is a drop in compressive residual stresses of $129 \mathrm{MPa}$ for the orthogonal residual stresses and a drop of $78 \mathrm{MPa}$ for the parallel residual stresses. This increase and subsequent decrease of the compressive residual stresses indicates a significant run-in phase. During this run-in phase, the grains blunt due to the mechanical stress, and grains reaching relatively far out of the bond break out. As a result, the contact area between the toric grinding pin and the material increases. The increasing contact area and the blunted grains lead to an increasing thermal load due to higher friction, which causes the compressive residual stresses to decrease again. For toric grinding pins used with the lateral grinding strategy, this run-in phase is unincisive. For toric grinding pins dressed with strategy A1 (blue), a steady increase in compressive residual stresses can be observed. Due to the principle of action during crushing and the occurring load during the grinding process, the self-sharpening effect is accelerated. The mechanical and thermal stress on the active partners is reduced by the breaking of the bond and the widely protruding grains. The stepwise release of new grain layers increases the degree of plastic deformation, which results in increasing residual compressive stresses. After the run-in phase, with the frontal grinding strategy from a machined volume of approx. $340 \mathrm{~mm}^{3}$ a constant residual stress state is established. With the lateral grinding strategy from a machined volume of approx. $110 \mathrm{~mm}^{3}$, a constant increase of compressive residual stress can be seen. This shows that the dressing strategy has a direct influence on the application behavior during the run-in phase.

Further consideration of the development of residual stresses as a function of the machined volume shows for the frontal strategy that the residual stresses remain at a constant level with increasing machined volume. Here, the crushed toric grinding pin induces on average $13 \%$ less compressive residual stresses orthogonal to the cutting direction and 9\% less compressive residual stresses parallel to the cutting direction. After a machined volume of $\mathrm{V}_{\mathrm{Wst}}=804 \mathrm{~mm}^{3}$, there is a difference of $\sigma=119 \mathrm{MPa}$ for the orthogonal residual stresses and $\sigma=77 \mathrm{MPa}$ for parallel residual stresses between the two dressing strategies. Therefore, from the different levels of the induced residual stresses, a correlation with the selected dressing process is evident. For the lateral strategy, after the run-in phase, the compressive residual stresses increase linearly with increasing machined volume for both dressing strategies. The crushed toric grinding pin induces on average $4.5 \%$ less compressive residual 
stresses orthogonal as well as parallel to the cutting direction. The maximum difference is $\sigma=92 \mathrm{MPa}$ for residual stresses orthogonal to the cutting direction and $\sigma=53 \mathrm{MPa}$ for residual stresses parallel to the cutting direction. It is evident that the influence of the dressing process on the level of induced residual stresses is not as pronounced for the lateral grinding strategy as it is for the frontal grinding strategy. The influence of the dressing strategy on the course of the induced compressive residual stresses can be explained by tool wear. The frontal strategy more often results in selfsharpening and thus in a comparatively consistent change of the geometry of the toric grinding pin. This in turn results in a change of the mechanical stress on the workpiece surface. This does not apply for the lateral grinding strategy. The observed clogging of these toric grinding pins indicates that self-sharpening occurs less frequently and the tools are therefore more blunt until self-sharpening occurs. With a blunting of the abrasive grains, the mechanical load on the workpiece becomes higher, which is reflected in the development of higher compressive residual stresses. This coincides with the different characteristics of the occurred clogging after grinding. The lower residual compressive stresses induced by crushed toric grinding pins can also be attributed to the self-sharpening effect, which reduces the load between tool and workpiece.

\section{Summary}

The aim of this study was to present a method to describe the dependency of the dressing process on the application and wear behavior for grinding of hardened AISI M3:2 $\left(\mathrm{ASP}^{\circledR} 2023\right)$ with toric cBN grinding pins. For this aim, vitrified bonded toric grinding pins were dressed using two different strategies. On the one hand, the tools were dressed by means of crushing $\left(\mathrm{q}_{\mathrm{d}}=1\right)$, on the other hand by means of conventional dressing $\left(\mathrm{q}_{\mathrm{d}}=0.8\right)$. A defined volume of $\mathrm{V}_{\mathrm{Wst}}=804 \mathrm{~mm}^{3}$ was machined using two different grinding strategies. To determine the tool wear behavior, the pin surfaces were qualitatively evaluated before and after the grinding tests and the geometries of the pins were measured. The G-ratio was then calculated from the measured values of the torus radii as an indicator for wear behavior. The application behavior was then shown on the basis of the induced residual stresses as a function of the machined volume. Due to the different process kinematics and geometric contact sizes of the two grinding strategies, a comparison of the application and wear behavior between the grinding strategies used here is only possible to a limited extent. However, within the framework of these investigations, it was possible to show the extent of tool wear and the resulting application behavior as a function of the dressing strategy for the respective grinding strategies. The main results are:
- The level of clogging on the toric grinding pins is significantly influenced by the selected grinding strategy and the resulting geometric contact values. In the case of the lateral grinding strategy, there is a small cross-section of engagement with a simultaneously large contact length. As a result, the thermal tool load is distributed over a small annular area of the toric grinding pin. That favors welding of the chip. The dressing strategy does not seem to have any influence here. On the other hand, in the case of the frontal grinding strategy, the dressing process influences clogging on the surface. The combination of additional transverse loading of the grains and the active principle of crushing leads to an almost clog-free tool surface.

- The G-ratio in the frontal grinding strategy shows that tool wear is influenced by the dressing strategy. Here, crushing leads to a considerable decrease in torus radius due to the active principle, which is further favored by the transverse forces acting in the frontal grinding strategy, resulting in a lower G-ratio.

- Regardless of the dressing or grinding strategy, there is an initial run-in phase. The intensity of this run-in phase depends on the selected dressing and grinding strategy.

- The influence of the dressing strategy on the maximum induced residual stresses depends mainly on the grinding strategy used. For the frontal grinding strategy, there is an influence of up to $13 \%$ on the maximum induced compressive residual stresses. In the case of the lateral grinding strategy, only a maximum of $4.5 \%$. The lower compressive residual stresses for crushed toric grinding pins can be attributed to the self-sharpening effect, which reduces the loads between tool and workpiece.

The results show that the presented method can be used to determine the dependency of the application and wear behavior on the dressing process. For a deeper understanding of individual influencing factors, further investigations are necessary, which will be performed in the future.

Acknowledgements The authors gratefully acknowledge the German Research Foundation (DFG) for the founding of the subproject B8 "Grinding strategies for local and stress orientated subsurface modification of sheet-bulk metal forming tools" of the Transregional Collaborative Research Centre on sheet-bulk metal forming (TCRC73).

Funding Open Access funding enabled and organized by Projekt DEAL.

Open Access This article is licensed under a Creative Commons Attribution 4.0 International License, which permits use, sharing, adaptation, distribution and reproduction in any medium or format, as long as you give appropriate credit to the original author(s) and the source, provide a link to the Creative Commons licence, and indicate if changes were made. The images or other third party material in this article are included in the article's Creative Commons licence, unless indicated otherwise in a credit line to the material. If material is not included in 
the article's Creative Commons licence and your intended use is not permitted by statutory regulation or exceeds the permitted use, you will need to obtain permission directly from the copyright holder. To view a copy of this licence, visit http://creativecommons.org/licenses/by/4.0/.

\section{References}

1. Hetzner H, Koch J, Tremmel S, Wartzack S, Merklein M (2011) Improved sheet bulk metal forming processes by local adjustment of tribological properties. J Manuf Sci Eng 133(6):1-11. https:// doi.org/10.1115/1.4005313

2. Merklein M, Koch J, Opel S, Schneider T (2011) Fundamental investigations on the material flow at combined sheet and bulk metal forming process. CIRP Ann Manuf Technol 60(1):283-286. https://doi.org/10.1016/j.cirp.2011.03.146

3. Lange K, Hettig A, Knörr M (1992) Increasing tool life in cold forging through advanced design and tool manufacturing. J Mater Process Technol 35(3-4):495-513. https://doi.org/10.1016/09240136(92)90337-R

4. Abrão AM, Denkena B, Köhler J, Breidenstein B, Mörke T (2015) The inducement of residual stress through deep rolling of AISI 1060 steel and its subsequent relaxation under cyclic loading. Int J Adv Manuf Technol 79(9):1939-1947. https://doi.org/10.1007/ s00170-015-6946-0

5. Lucas H, Denkena B, Grove T, Krebs E, Wiederkehr P, Freiburg D, Biermann D (2015) Analysis of residual stress states of structured surfaces manufactured by high-feed and micro-milling. HTM J Heat Treat Mater 70(4):183-189. https://doi.org/10.3139/ 105.110265

6. Tönshoff HK, Böß V, Urban B (2002) Automated finishing of dies and molds. Prod Eng Res Dev Ger 9(2):1-4
7. Denkena B, Grove T, Lucas H (2016) Influences of grinding with Toric CBN grinding tools on surface and subsurface of 1.3344 PM steel. J Mater Process Technol 229:541-548. https://doi.org/ 10.1016/j.jmatprotec.2015.09.039

8. Stuff D (1997) Einsatzvorbereitung keramisch gebundener CBNSchleifscheiben. Dr.-Ing. Diss., Aachen, RWTH Aachen, WZL

9. Brinksmeier E, Cinar M (1995) Characterization of dressing processes by determination of the collision number of the abrasive grits. CIRP Ann 44(1):299-304. https://doi.org/10.1016/S00078506(07)62330-0

10. Erasteel. https://www.erasteel.com/products/asp2023/. Accessed 23 Aug 2021

11. Grove T, Lucas H, Denkena B (2018) Residual stresses in grinding of forming tools with toric grinding pins. Proc CIRP 71:354-357. https://doi.org/10.1016/j.procir.2018.05.040

12. Denkena B, Köhler J, van der Meer M (2013) A roughness model for the machining of biomedical ceramics by toric grinding pins. CIRP J Manuf Sci Technol 6(1):22-33. https://doi.org/10.1016/j. cirpj.2012.07.002

13. Denkena B, de Leon L, Behrens L (2010) Contact conditions in 5-axis-grinding of double curved surfaces with toric grinding wheels. Adv Mater Res 126-128:41-46. https://doi.org/10.4028/ www.scientific.net/AMR.126-128.41

14. van der Meer M (2011) Bearbeitung keramischer Funktionsflächen für Knieimplantate. Dr.-Ing. Diss., Garbsen, Leibniz Universität Hannover, IFW

15. Macherauch E, Müller P (1961) Das $\sin ^{2}(\psi)$-Verfahren der röntgenographischen Spannungsmessung. Z Angew Phys 7:305-312

Publisher's Note Springer Nature remains neutral with regard to jurisdictional claims in published maps and institutional affiliations. 